\title{
An armadillo-domain protein participates in a telomerase interaction network
}

\author{
Ladislav Dokládal ${ }^{1,2,6} \cdot$ Eva Benková $^{3} \cdot$ David Honys $^{4} \cdot$ Nikoleta Dupláková $^{4} \cdot$ Lan-Ying Lee $^{5} \cdot$ Stanton B. Gelvin ${ }^{5}$. \\ Eva Sýkorová ${ }^{10}$
}

Key message Arabidopsis and human ARM protein interact with telomerase. Deregulated mRNA levels of DNA repair and ribosomal protein genes in an Arabidopsis arm mutant suggest non-telomeric ARM function. The human homolog ARMC6 interacts with hTRF2.

Abstract Telomerase maintains telomeres and has proposed non-telomeric functions. We previously identified interaction of the C-terminal domain of Arabidopsis telomerase reverse transcriptase (AtTERT) with an armadillo/ $\beta$-catenin-like repeat (ARM) containing protein. Here we explore protein-protein interactions of the ARM protein, AtTERT domains, POT1a, TRF-like family and SMH family proteins, and the chromatin remodeling protein CHR19 using bimolecular fluorescence complementation $(\mathrm{BiFC})$, yeast two-hybrid $(\mathrm{Y} 2 \mathrm{H})$ analysis, and co-immunoprecipitation. The ARM protein interacts with both the $\mathrm{N}$ - and C-terminal domains of AtTERT in different cellular compartments. ARM interacts with CHR19 and TRFlike I family proteins that also bind AtTERT directly or through interaction with POT1a. The putative human ARM homolog co-precipitates telomerase activity and interacts with hTRF2 protein in vitro. Analysis of Arabidopsis arm mutants shows no obvious changes in telomere length or telomerase activity, suggesting that ARM is not essential for telomere maintenance. The observed interactions with telomerase and Myb-like domain proteins (TRF-like family I) may therefore reflect possible non-telomeric functions. Transcript levels of several DNA repair and ribosomal genes are affected in arm mutants, and ARM, likely in association with other proteins, suppressed expression of XRCC3 and RPSAA promoter constructs in luciferase reporter assays. In conclusion, ARM can participate in non-telomeric functions of telomerase, and can also perform its own telomerase-independent functions.

Keywords Armadillo/ $\beta$-catenin-like repeat · ARMC6 $\cdot$ AtTERT $\cdot$ Homologous recombination $\cdot$ Protein-protein interaction · Telomerase activity

\section{Introduction}

Telomerase is a conserved ribonucleoprotein complex that is responsible for telomere synthesis (Greider and Blackburn

Electronic supplementary material. 1985, 1987), compensating telomere shortening in cells with

Eva Sýkorová

evin@ibp.cz

1 Institute of Biophysics, The Czech Academy of Sciences, Královopolská 135, 61265 Brno, Czech Republic

2 Laboratory of Functional Genomics and Proteomics, NCBR, Faculty of Science, Masaryk University, Brno, Czech Republic

3 Institute of Science and Technology Austria, 3400 Klosterneuburg, Austria

4 Institute of Experimental Botany, The Czech Academy of Sciences, Rozvojova 263, 16502 Prague, Czech Republic

5 Department of Biological Sciences, Purdue University, West Lafayette, IN 47907-1392, USA

6 Present Address: Department of Biology, Faculty of Science and Medicine, University of Fribourg, Fribourg, Switzerland 
high proliferative needs such as in animal embryonic, stem, and cancer cells (reviewed in Blasco 2005), plant meristematic cells, and tissue culture cells (Fajkus et al. 1996; Fitzgerald et al. 1996). Telomerase activity requires two core subunits, telomerase reverse transcriptase (TERT) and telomerase RNA, which are associated with additional proteins to form the telomerase complex in vivo (Collins 2006). In most organisms, the TERT subunit has an evolutionarily conserved primary structure comprising a telomerase essential N-terminal (TEN) domain, a telomerase RNA binding domain, a central reverse transcriptase (RT) domain, and a C-terminal extension (CTE). Whereas the RT domain is responsible for telomerase enzymatic activity, the $\mathrm{N}$ - and C-terminal parts of TERT also represent potential targets for telomerase accessory and regulatory proteins. In plants, tandem affinity purification of Arabidopsis thaliana TERT showed that AtPOT1a protein is a component of the Arabidopsis telomerase holoenzyme and interacts with AtTERT in vivo (Majerska et al. 2017). This observation is consistent with previous findings that the AtTERT-V(I8) splicing isoform physically interacts with POT1a (Rossignol et al. 2007), potla mutants display progressive telomere shortening, and telomerase activity can be immunoprecipitated using POT1a antibodies (Surovtseva et al. 2007). Protein components associated with Arabidopsis telomeres (see Prochazkova Schrumpfova et al. 2016 for review) differ significantly from human shelterin formed by proteins TRF1, TRF2, TIN2, TPP1, RAP1 and POT1 (de Lange 2005). Human POT1 binds the telomeric 3' DNA overhang and is not a component of the human telomerase holoenzyme complex. However, the shelterin subcomplex POT1-TPP1 binds telomeric DNA and its interaction (via TPP1) with the TEN domain of hTERT increases telomerase processivity (Zaug et al. 2010). The key components of human shelterin are the Myb domain-containing proteins TRF1 and TRF2 that bind double-strand telomeric DNA (Broccoli et al. 1997; Chong et al. 1995). Based on sequence similarities with hTRF Myb domains, the TRF-like (TRFL) proteins (family I and II) were identified in Arabidopsis. However any function of these proteins in telomere maintenance has not previously been demonstrated (Fulcher and Riha 2015). Telomeric functions in vivo were recently demonstrated for the plant-specific Single Myb Histone (SMH) proteins (Dvorackova et al. 2015; Schrumpfova et al. 2014). Moreover, the SMH proteins may function as chromatin modulators: they bind promoter regions of genes involved in ribosome biogenesis (Schrumpfova et al. 2016; Zhou et al. 2016) and of other genes containing a telobox, a regulatory motif with a sequence identical to that of the plant telomeric repeat (AAACCCT)n (Regad et al. 1994). Similar to SMH proteins, the TRF-like family I proteins can bind telomeric dsDNA in vitro (Karamysheva et al. 2004) and their putative homologs from parsley and maize are implicated in regulating gene expression (da Costa e Silva et al. 1993; Lugert and Werr 1994; Nagaoka and Takano 2003).

Non-canonical activities of plant telomerase have not yet been reported. Several studies have described non-telomeric (non-canonical) functions of mammalian telomerase. These include involvement in regulating cellular processes such as apoptosis, cellular proliferation, and cell cycle progression. Moreover, hTERT expression and telomerase activity are linked to tumorigenesis by telomere length-independent mechanisms (reviewed in Majerska et al. 2011). The most discussed function is the participation of mammalian telomerase and armadillo/ $\beta$-catenin proteins in the Wnt pathway that was first identified for its role in carcinogenesis. However, similar effector proteins in plants are unknown (see Sharma et al. 2014 for review). Our previous search for AtTERT partners identified two proteins from an Arabidopsis cDNA library that interacted with the CTE domain (Lee et al. 2012). One of these was an RNA-recognitionmotif (RRM)-containing protein that also interacted with proteins responsible for transcriptional and post-transcriptional regulation (Dokladal et al. 2015). The second protein of unknown function was an armadillo/ $\beta$-catenin-like repeat (ARM, encoded by AT4G33945) protein that interacted with the CTE domain of AtTERT, predominantly in the cytoplasm of BY-2 protoplasts (Lee et al. 2012). The ARM protein contains four armadillo/ $\beta$-catenin-like repeats. Except for the presence of these repeats, its primary structure does not resemble mammalian or plant armadillo proteins with clear biological functions, such as importins, kinesins, ubiquitin ligases, or kinases (see Coates 2003; Tewari et al. 2010, and references herein). However, in searching for putative telomere links we found a putative human homologue of the ARM protein ARMC6 among proteins that co-purified with hTRF2 (Giannone et al. 2010), a core component of the human shelterin complex. The function of ARMC6 has not yet been determined.

Here, we report the localization of the Arabidopsis ARM protein and mutual protein-protein interactions of ARM, Arabidopsis telomerase holoenzyme (AtTERT and POT1a), Myb domain-containing proteins (TRFL and SMH families), and the chromatin remodeling protein CHR19. Telomere length and telomerase activity were not influenced by disruption of the ARM gene, whereas mRNA levels of several ribosomal genes and genes involved in the homologous recombination pathway were altered in arm mutants. A putative human homolog of ARM co-precipitated human telomerase activity in vitro, suggesting that the interaction between ARM proteins and telomerases may be evolutionarily conserved. 


\section{Materials and methods}

\section{Plant material}

Arabidopsis T-DNA insertion lines SALK_063839C (arm1) and SALK_150486C (arm-2) (Alonso et al. 2003) were obtained from the Nottingham Arabidopsis Stock Centre. The tert line (SAIL_284_B07) was described by Fojtova et al. (2011). Seeds were surface sterilized and germinated on $0.8 \%$ (w/v) agar plates supplemented with $1 / 2$ Murashige and Skoog media (MS; cat. n. M0255.0050; Duchefa, http:// www.duchefa-biochemie.com) and 1\% (w/v) sucrose. Seedlings were potted after 7 days and further grown under conditions of $16 \mathrm{~h}$ light, $21^{\circ} \mathrm{C}$ and $8 \mathrm{~h}$ dark, $19{ }^{\circ} \mathrm{C}$, illumination $150 \mu \mathrm{mol} \mathrm{m} \mathrm{m}^{-2} \mathrm{~s}^{-1}$. Individual plants from each T-DNA insertion line were genotyped (see Supplemental Table S1 for primer sequences) and homozygous mutant plants were grown. Nicotiana benthamiana plants were grown under conditions of $8 \mathrm{~h}$ light, $21{ }^{\circ} \mathrm{C}$ and $16 \mathrm{~h}$ dark, $19{ }^{\circ} \mathrm{C}$, illumination $100 \mu \mathrm{mol} \mathrm{m} \mathrm{m}^{-2} \mathrm{~s}^{-1}$.

\section{Telomere length and telomerase activity analyses}

Terminal restriction fragment (TRF) analysis, the conventional telomere repeat amplification protocol (TRAP), and the quantitative TRAP assays were performed as described (Fojtova et al. 2011). Mean telomere length values were calculated using TeloTool software (Gohring et al. 2014). The TRAP assay with co-immunoprecipitated human telomerase is described in Supplemental materials and methods.

\section{Entry clone generation}

Sequences encoding the coding regions of ARM (AT4G33945), TRFL3 (AT1G17460), TRFL6 (AT1G72650), TRFL9 (AT3G12560), TRFL1 1 (AT5G58340) and POT1a proteins (AT2G05210) were amplified from 7-day-old seedling cDNA, and TRFL2 (AT1G07540) from pollen cDNA using Phusion HF DNA polymerase (Finnzymes, http://www.thermoscientificbio. com/finnzymes) according to the manufacturer's instructions. Primers used for cloning are listed in Supplemental Table S1. PCR products were cloned into pDONR/Zeo (Invitrogen, http://www.lifetechnologies.com) using Gateway technology. An entry clone encoding CHR19 (stock no. U16514, AT2G02090) was obtained from the ABRC (http:// www.arabidopsis.org/). Entry clones encoding AtTERT (AT5G16850) fragments TEN(1-233), RID1(1-271), Fw3N-NLS(229-582), RT(597-987), CTE2(958-1123) were prepared previously (Zachova et al. 2013).

\section{Yeast two hybrid (Y2H) and co-immunoprecipitation (co-IP) analyses}

$\mathrm{Y} 2 \mathrm{H}$ experiments were performed using the Matchmaker ${ }^{\mathrm{TM}}$ GAL4-based two-hybrid system (Clontech, http://www. clontech.com). cDNA sequences encoding ARM, TRFL2, TRFL3, TRFL6, TRFL9, TRFL11, POT1a, CHR19 and TERT fragments were subcloned from their entry clones into the destination vectors pGADT7-DEST and pGBKT7DEST. TRB1 (AT1G49950), TRB2 (AT5G67580), and TRP1 (AT5G59430) constructs in pGADT7 and pGBKT7 vectors were prepared previously (Kuchar and Fajkus 2004). Each bait/prey combination was co-transformed into Saccharomyces cerevisiae PJ69-4a and $\mathrm{Y} 2 \mathrm{H}$ analysis was performed as described in (Schrumpfova et al. 2014) using TRB1-RID interaction as a positive control. Protein expression was verified by immunoblotting using mouse anti-HA (kindly provided by Bořivoj Vojtěšek, Masaryk university Brno, Czech Republic) or mouse anti-myc primary antibodies and a HRP-conjugated anti-mouse secondary antibody (both Sigma-Aldrich, http://www.sigma-aldrich.com) (Supplemental Fig. S1a). In vitro translation of bait/prey proteins was performed using the same constructs as in the Y2H system (vectors pGADT7-DEST and pGBKT7-DEST with minimal T7 promoter) and a TNT quick coupled transcription/ translation system (Promega, https://www.promega.com) in $25 / 50 \mu \mathrm{l}$ reaction volumes according to the manufacturer's instructions. Prey proteins were radioactively labeled using ${ }^{35}$ S-Met (Hartmann Analytic, Germany). The co-IP procedure was performed as described by Schrumpfova et al. (2014) using mouse anti-myc antibody (9E10, Sigma) and magnetic beads Dynabeads $®$ Protein G (Life Technologies, https://www.thermofisher.com). Proteins in input, unbound, and bound fractions were separated by $12.5 \%$ SDS-PAGE, blotted onto Amersham Hybond-ECL membranes (GE Healthcare, http://www.gelifesciences.com/), and analyzed using an FLA7000 imager (Fujifilm).

\section{Bimolecular fluorescence complementation (BiFC)}

pSAT1-nEYFP-C1::RID1, pSAT1-nEYFP-C1::TRP1, pSAT1-cEYFP-C1-B::RID1, and pSAT5-DEST-cEYFPC1(B)::ARM constructs used for BiFC in tobacco BY-2 protoplasts were prepared previously (Lee et al. 2012; Schrumpfova et al. 2014). Tobacco BY-2 protoplasts were isolated and transfected as described (Tenea et al. 2009; Lee et al. 2012). To label cell nuclei, we co-transfected a plasmid expressing mRFP fused to the nuclear localization signal of the VirD2 protein from Agrobacterium tumefaciens (mRFPVirD2(NLS); Citovsky et al. 2006). For BiFC in N. benthamiana leaves, cDNA sequences encoding TRFL2/3/6/9, CHR19, ARM, and TERT fragments (RID1 and RT) were subcloned from their entry clones into the binary destination 
vectors pE-SPYNE-GW (for N-terminal nYFP tag) and/or pE-SPYCE-GW (for N-terminal cYFP tag) that were kindly provided by Caroline Mayer and Wolfgang Dröge-Laser (University of Göttingen; Mayer and Dröge-Laser, unpublished results). The constructs were electroporated into Agrobacterium tumefaciens GV3101 and the transformants were selected on YEP medium containing $40 \mu \mathrm{g} / \mathrm{ml}$ carbenicillin. Agrobacterium cultures with nYFP-, cYFP-, p19 [to prevent gene silencing (Voinnet et al. 2000)], and pK7RWG2::ATHOOK (AT1G48610; to label cell nuclei) constructs were grown to $\mathrm{A}_{600}=0.8$ and used for transient expression in $N$. benthamiana leaves via syringe infiltration in a ratio of 1:1:1:1. After 3 days incubation, fluorescence was observed using a Zeiss Observer.Z1 equipped with an LSM780 confocal unit. Protein expression was tested by immunoblotting using an anti-GFP primary antibody (Roche, http://www. roche.com) and a HRP-conjugated anti-mouse secondary antibody (Sigma-Aldrich, http://www.sigma-aldrich.com). Protein extracts were prepared according to Heinekamp et al. (2002). As negative controls, we used nYFP- and cYFPGAUT10 (AT2G20810) constructs. The pMDC43::ARM construct was used to visualize GFP-ARM subcellular localization in N. benthamiana leaves, and the PM-RB construct described by Nelson et al. (2007) was used as a plasma membrane marker.

\section{Analysis of human proteins}

We prepared constructs of armadillo repeat-containing protein 6 (ARMC6) coding for isoform 2 (Genebank accession NP_219483.1) in pBluescript-SK or pDONRZeo vectors using sequence-specific PCR primers and cDNA from the human cell line MCF7 using Superscript III reverse transcriptase (Invitrogen, http://www.lifetechnologies.com). The constructs TRF2 and TPP1 in pDONR/Zeo, and Rap1 in pHGWA (Janouskova et al. 2015) were kindly provided by Ctirad Hofr (CEITEC MU Brno, Czech Republic). The ARMC6, TRF2, and TPP1 inserts were introduced into pGBKT7-DEST and pDEST17 vectors using Gateway technology (Invitrogen, http://www.lifetechnologies.com) or into the pTriEx 4 vector by ligation. The construct hTERT-hTR in pBluescript-SK (Bachand et al. 2000) was kindly provided by Chantal Autexier (McGill University, Montreal, Quebec, Canada). Preparation of constructs of human proteins created for this work, in vitro expression in RRL, co-immunoprecipitation, and TRAP assays are described in detail in Supplemental Materials.

\section{RNA isolation and RT-qPCR analysis}

Various Arabidopsis pollen developmental stages were collected according to (Dupl'akova et al. 2016) and RNA was isolated using a Plant RNeasy Kit (Qiagen, http://www. qiagen.com) according to the manufacturer's instructions, and further purified by DNaseI treatment (see Supplemental Material for details and specific RT-qPCR conditions). RNA isolation from other plant tissues and reverse transcription were performed as described (Fojtova et al. 2011; Ogrocka et al. 2012). Calli were derived from 7-day-old seedlings, propagated on cultivation medium with $1 \mu \mathrm{g} \mathrm{ml}^{-1} 1$-naphthaleneacetic acid and $1 \mu \mathrm{g} \mathrm{ml}^{-1} 2,4$-dichlorophenoxyacetic acid, and subcultured monthly onto fresh medium.

Transcript levels relative to a ubiquitin reference gene (ubi-10) were analyzed in plant tissues using FastStart SYBR Green Master (Roche). A $1 \mu \mathrm{l}$ of cDNA was added to the $20 \mu \mathrm{l}$ reaction mix; the final concentration of each forward and reverse primer (Supplemental Table S1) was $0.5 \mu \mathrm{M}$. Reactions were performed in triplicate. PCR cycle conditions consisted of 10 min of initial denaturation $\left(95^{\circ} \mathrm{C}\right)$ followed by 40 cycles of $20 \mathrm{~s}$ at $95{ }^{\circ} \mathrm{C}, 30 \mathrm{~s}$ at $55^{\circ} \mathrm{C}$, and $1 \mathrm{~min}$ at $72{ }^{\circ} \mathrm{C}$. SYBR Green I fluorescence was monitored after each extension step. The amount of the respective transcript was determined for at least two biological replicates (for details see Supplemental Table S3) using the $\Delta \Delta \mathrm{Ct}$ method (Pfaffl 2004).

\section{Luciferase assay}

Sequences 500 or $1000 \mathrm{bp}$ upstream from the translation start of genes encoding RPSAA (AT1G72370) and XRCC3 (AT5G57450) were fused with the firefly luciferase coding sequence and cloned into pM42GW7 ("reporter"). The ARM coding sequence was cloned into the expression vector p2GW7 under control of the CaMV 35S promoter ("effector"). A p2GW7::GUS construct was used as a reference. Arabidopsis protoplasts were freshly prepared from a root cell suspension culture (Simaskova et al. 2015) and transfected with $3 \mu \mathrm{g}$ each of reporter- and effector/referenceencoding plasmids and $1 \mu \mathrm{g}$ of plasmid encoding control Renilla luciferase. Both firefly and Renilla luciferase activities were measured $16 \mathrm{~h}$ after transfection using the DualLuciferase Reporter Assay System (Promega) on a Synergy H1 microplate reader (Bio-Tek) at 12 one-second intervals. To eliminate the effect of different transfection efficiencies, total firefly luciferase activity was divided by total Renilla luciferase activity (fluc/rluc). Relative promoter activity was calculated as (fluc/rluc) $)_{\text {effector: }}$ (fluc/rluc) $)_{\text {reference. }}$ The experiment was performed using three biological replicas. 


\section{Results}

\section{The ARM protein interacts with the $\mathrm{N}$ - and C-terminal domains of AtTERT}

By BiFC screening of a cYFP-tagged cDNA library in tobacco BY-2 protoplasts (Lee et al. 2012), we previously identified the ARM protein as an interacting partner with the C-terminal domain (CTE2) of AtTERT. To verify this interaction, we employed a yeast-two-hybrid (Y2H) system. The results confirmed ARM-CTE2 interaction using histidine growth selection (Fig. 1a). We further investigated ARM interactions with other AtTERT protein fragments covering all conserved TERT regions [TEN, RID1, Fw3N-NLS, RT; naming convention is from Zachova et al. (2013)], and with another component of the Arabidopsis telomerase holoenzyme complex, POT1a (summarized in Supplemental Table S2). Among these, ARM interaction with the $\mathrm{N}$-terminal TERT fragment RID1 was observed on both histidine and stringent adenine selection plates (Fig. 1a). Using BiFC, we confirmed that ARM-RID1 interaction occurred exclusively within the nucleus, including the nucleolus, of tobacco BY-2 protoplasts (Fig. 1b). The previously described interaction, ARM-CTE2, occurred predominantly in the cytoplasm (Lee et al. 2012). To determine the natural localization of the ARM protein, we transiently expressed a GFP-ARM fusion protein in $N$. benthamiana leaves. In addition to nuclear and cytoplasmic localization, the GFP-ARM protein co-localized with a plasma membrane marker (Fig. 1c and Supplemental Fig. S2). Variable localization of ARM protein and its interactions suggests ARM may perform its biological functions outside of the nucleus in addition to possible ARM-mediated functions of telomerase.

\section{The ARM protein interacts with TRF-like family I proteins}

We identified a putative human homologue (ARMC6) of the AtARM protein in the dataset of (Giannone et al. 2010) among proteins that co-purify with the telomere binding protein hTRF2. We therefore investigated interactions of the AtARM protein with representative members of the TRF-like family I (TRP1, TRFL2 and TRFL9) and the TRF-like family II (TRFL3, TRFL6, TRFL11). Despite their sequence similarity to human TRFs, these proteins do not function in telomere maintenance (Fulcher and Riha 2015). Thus, we also tested telomeric proteins from the plant-specific SMH family (TRB1, TRB2). TRP1 and TRFL9 proteins are distant relatives within the TRF-like I family and they can form heterodimers in vitro (Karamysheva et al. 2004). TRFL2 shows specific expression in the gametophyte (Fig. 1d). TRFL3 and TRFL6 are close relatives among members of the TRF-like family II (Karamysheva et al. 2004; Yanhui et al. 2006) but they show strikingly different transcriptional profiles with highly induced TRFL3, but not TRFL6, gene expression in response to DNA damage (Culligan et al. 2006) and in tert-/- mutants with eroded telomeres (Amiard et al. 2014). TRFL11 was identified among proteins that copurified with AtTERT (Majerska et al. 2017). Investigation of protein-protein interactions by $\mathrm{Y} 2 \mathrm{H}$ revealed positive interactions of two proteins from the TRF-like family I (TRP1 and TRFL2) with the ARM protein on histidine growth selection (Supplemental Table S2, Fig. 1a). Using BiFC, the TRP1-ARM and TRFL2-ARM interactions were detected in nuclei of tobacco BY-2 protoplasts and $N$. benthamiana leaves, respectively (Fig. 1b). For an unknown reason, TRFL9 interactions in $\mathrm{Y} 2 \mathrm{H}$ were not reproducible; we therefore tested co-IP of proteins expressed in a rabbit reticulocyte lysate (RRL) in vitro. Using this assay, TRFL9-ARM interaction was negative (Supplemental Table S2, Fig. 1e), whereas we observed a positive interaction of TRFL9 with ARM using BiFC (Fig. 1b). It is possible that this BiFC interaction is not direct but rather mediated by another protein in vivo, or it may depend on a specific posttranslational modification that is available in plant cells but not in yeast or in an in vitro system. The ARM protein did not interact with either the TRF-like family II protein TRFL11, or with the SMH proteins TRB1 and TRB2 using a $\mathrm{Y} 2 \mathrm{H}$ analysis (Supplemental Table S2, Fig. 1a). Interactions of the TRFlike family II proteins TRFL3 and TRFL6 could not be investigated in a $\mathrm{Y} 2 \mathrm{H}$ because the BD-TRFL $3 / 6$ constructs alone showed growth on plates with high 3-aminotriazole concentrations, and AD-TRFL3/6 constructs were not expressed in yeast (Supplemental Fig. S1a). Importantly, no interaction was observed between the TRFL3/6 proteins and the ARM protein using BiFC in $N$. benthamiana leaves (Fig. 1b), despite proven protein expression (Supplemental Fig. S1a). In conclusion, our results demonstrate interactions of the ARM protein exclusively with TRF-like family I proteins (TRP1, TRFL2, TRFL9) using the techniques of BiFC, Y2H, and/or co-IP (summarized in Supplemental Table S2 and Fig. 1f).

\section{Putative protein-protein interaction network of AtTERT, ARM, and Myb domain-containing proteins}

Positive interactions of the ARM protein with two AtTERT domains and with TRFL family I proteins encouraged us to test for interactions of TRFL proteins with telomerase holoenzyme components represented by AtTERT fragments and POT1a. Investigation of a putative protein-protein 


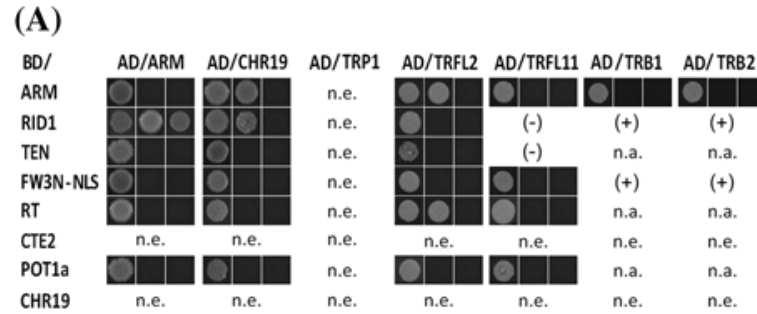

AD/ BD/ARM BD/CHR19 BD/TRP1 BD/TRFL2 BD/TRFL11 BD/TRB1 BD/TRB2

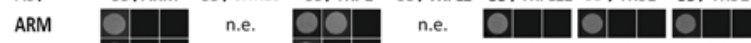

CTE2

POT1a

CHR19

(C)

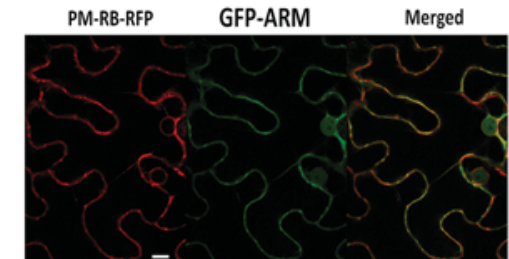

(D)

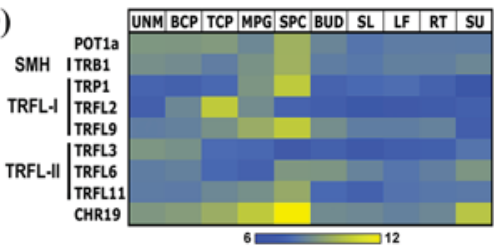

(E)

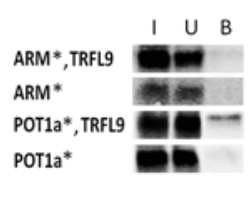

(B)

BYFP-RID

nYFP-CHR19
CYFP-ARM

nYFP-CHR19

nYFP-CHR19
CYFP-RID1

$\begin{array}{cccc}\text { n.e. } & (-) & (+) & (+) \\ \text { n.e. } & (-) & \text { n.a. } & \text { n.a. } \\ & -(+) & (+)\end{array}$

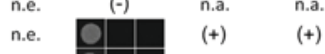

n.e.

n.e.

n.e.

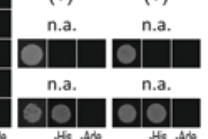

NYFP-TRFL2

CYFP-ARM

nYFP-TRFL2
CYFP-RT

nYFP-TRFL2
CYFP-CHR19

nYFP-TRFL3

CYFP-ARM
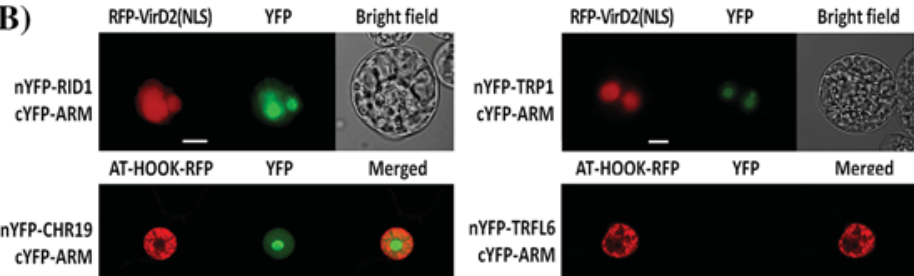

6

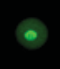

8
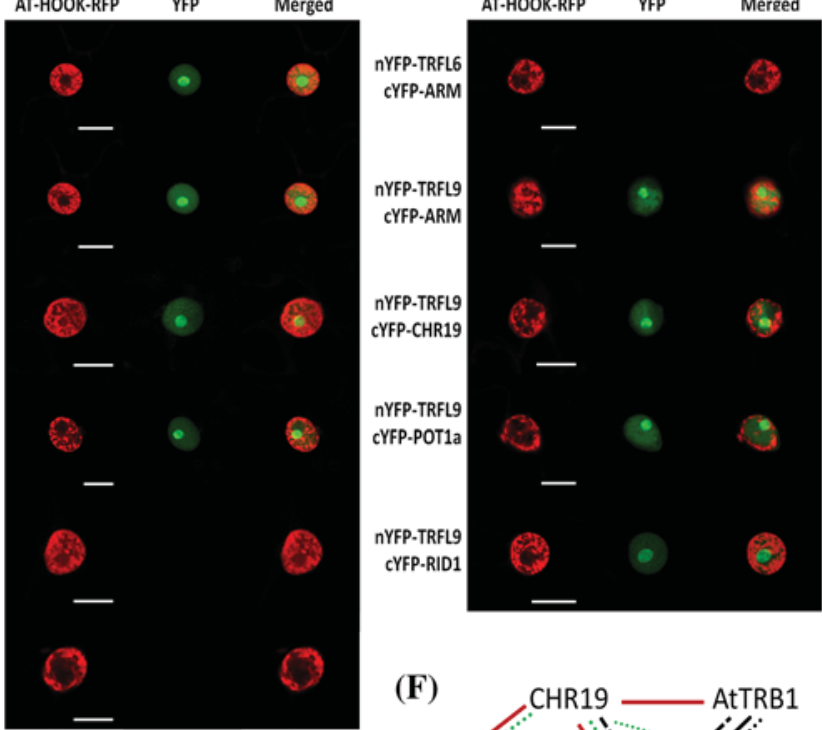

(F)

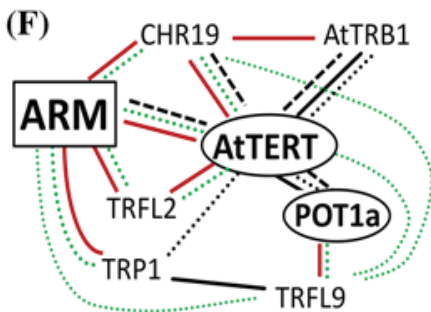

Fig. 1 Protein-protein interactions and subcellular localization of the ARM protein. a Yeast two-hybrid assay (Y2H), b bimolecular fluorescence complementation (BiFC) and e co-immunoprecipitation were used to study interactions among ARM, TERT fragments (RID1, TEN, FW3N-NLS, RT, and CTE2), POT1a, CHR19, and TRF-like proteins. The results are summarized in Supplemental Table S2. a $\mathrm{Y} 2 \mathrm{H}$ experiments were performed using protein constructs expressed in the vectors pGADT7-DEST (AD) and pGBKT7DEST (BD). Each bait/prey combination was co-transformed into Saccharomyces cerevisiae PJ69-4a and positive interactions were detected using histidine (-His) or histidine and adenine (-His, - Ade) growth selection. Interactions of TRFL11 and TRB proteins indicated (+/-) were reported in Majerska et al. (2017) and Schrumpfova et al. (2014), respectively; n.a. not analyzed; n.e. not expressed. $\mathbf{b}$ In BiFC assays, interactions between n/cYFP constructs of ARM and RID1 or TRP1 were detected in the nucleus, including the nucleolus, of tobacco BY-2 protoplasts (upper panels) and between ARM and TRFL2, TRFL9 or CHR19 in N. benthamiana leaf cells (bottom panels; only the nucleus is visible). Similar positive results were found for CHR19-RID1, CHR19-TRFL9, TRFL2RT, TRFL9-RID1, and TRFL9-POT1a interactions. Negative BiFC results indicated lack of interaction between TRFL2 and CHR19, and between ARM and TRF-like family II proteins (TRFL3, TRFL6, bottom panels), and with RT fragment (Supplemental Fig. S1b). n/ cYFP constructs and a mRFP-VirD2-NLS nuclear marker or p19 and AT-HOOK-RFP nuclear marker were co-transfected into protoplasts (upper panel) or Agrobacterum infiltrated into leaf cells (bottom panels), respectively. n/cYFP-GAUT10 constructs served as negative controls (Supplemental Fig. S1c). c GFP-ARM localized in the nucleus and in the plasma membrane of $N$. benthamiana leaf cells (lower panel, see also Supplemental Fig. S2), using a PM-RB-RFP construct to label the plasma membrane. YFP fluorescence (green), mRFP fluorescence (red). Scale bars $(\mathbf{b}, \mathbf{c})$ indicate $20 \mu \mathrm{m}$. d Heat map showing expression profiles of selected genes in various Arabidopsis tissues selected from publicly available transcriptomic datasets (Duplakova et al. 2007, see Supplemental Material for details). Expression signals are presented as $\log 2$ values. $U N M$ uninucleate microspores, $B C P$ bicellular pollen, $T C P$ tricellular pollen, $M P G$ mature pollen, $S P C$ sperm cells, $B U D$ flower buds, $S L$ seedlings, $L F$ leaves, $R T$ roots, $S U$ cell suspension. e Positive interaction between TRFL9 and POT1a protein was detected after immunoprecipitation using anti-c-myc antibody. TRFL9/c-myc protein (bait) and radioactively-labeled prey proteins (asterisk) were expressed in a rabbit reticulocyte lysate from plasmid vectors with a minimal $\mathrm{T} 7$ promoter. Proteins in input (I), unbound (U), and bound (B) fractions, water was used instead of TRFL9 protein in control samples. $\mathbf{f}$ Mutual proteinprotein interactions of ARM protein, Arabidopsis telomerase holoenzyme complex components (AtTERT, POT1a), TRF-like family I proteins (TRP1, TRFL2, TRFL9), SMH family protein TRB1, and chromatin remodeling protein CHR19 are indicated. The interactions detected experimentally here (in color) or reported previously (in black) using $\mathrm{Y} 2 \mathrm{H}$ and/or co-IP (lines) are mainly supported in planta by $\mathrm{BiFC}$ detection (dotted line) and tandem affinity co-purification (dashed line) 
interaction network showed interesting specific interactions among individual TRFL family I proteins. TRFL2 interacted exclusively with the RT domain of AtTERT in both Y2H and BiFC systems (Supplemental Table S2, Fig. 1a, b). TRFL9 interactions were investigated in vitro and a positive TRFL9-POT1a interaction was detected by co-IP (Fig. 1e) and further confirmed by BiFC (Fig. 1b). Moreover, a TRFL9-RID1 positive signal was observed in nuclei of $N$. benthamiana leaves (Fig. 1b) but not by co-IP (Fig. 1e). These results suggest that the TRFL9-RID1 interaction could be mediated by POT1a protein in vivo (Supplemental Table S2). We also tested the TRF-like family II protein TRFL11 but observed no interaction with AtTERT fragments or POT1a using a Y2H (Supplemental Table S2, Fig. 1a). Positive TRP1-RID1 interaction and strong interactions between SMH proteins and AtTERT were reported previously (Schrumpfova et al. 2014) (Fig. 1a, f). Thus, strikingly, both Myb domain-containing protein groups interacting with AtTERT and/or POT1a are known to bind telomeric repeats and can provide a functional link to transcriptional regulation.

\section{ARM, AtTERT, and telomere-binding proteins interact with the chromatin remodeling protein CHR19}

We identified CHR19 among proteins that co-purified with AtTERT fragments using tandem affinity purification (Majerska et al. 2017). CHR19 represents a protein with putative dual functions (Dona and Mittelsten Scheid 2015; and references therein). It is a presumed homolog of yeast Fun30 and human SMARCAD1 chromatin remodelers that promote DNA end resection. CHR19 was also identified as an interactor with histone lysine methyltransferase SUVR2 that is involved in transcriptional silencing, similar to Fun30 in yeast. We therefore tested whether CHR19 protein could interact with the ARM protein, telomerase complex components (AtTERT, POT1a), and proteins from the TRFL and SMH families. Using a Y2H system, we observed interactions for CHR19-ARM, CHR19-RID1, CHR19-TRB1, CHR19-TRB2 (Supplemental Table S2, Fig. 1a). Using BiFC, the interactions between CHR 19 and ARM, and CHR19 and RID1 were further localized within the nuclei of $N$. benthamiana leaf cells (Fig. 1b). The CHR19-TRFL2 interaction could not be investigated using a Y2H because the BD-TRFL2 and BD-CHR19 constructs were not expressed in yeast (Supplemental Fig. S1a), but we obtained a negative result using BiFC (Fig. 1b). The CHR19-TRFL9 interaction was negative in a co-IP assay (Fig. 1e) but was clearly detected in the BiFC experiment (Fig. 1b), suggesting that this interaction may be mediated by another protein partner in vivo or may depend on a specific posttranslational modification(s). These results provide an additional link to specialized functions of AtTERT that may be related to functions of CHR19 in the regulation of transcription and/or in DNA end resection, possibly relevant to its participation in chromosomal healing.

\section{ARM is highly expressed in flower buds, pollen, young leaves, and root tips}

Because the $A R M$ gene is missing on widely used microarray chips (Affymetrix Arabidopsis ATH1 Genome Array), data on tissue-specific ARM transcription have not been available from public databases. To obtain a transcriptional profile of the $A R M$ gene and to compare it with that of the AtTERT gene (Fig. 2), we analyzed ARM expression during plant development with a focus on telomerase-positive tissues. We used RT-qPCR to quantify $A R M$ transcripts in flower buds, calli, leaves, and 7-day-old seedlings of wildtype plants (Col-0), with a particular interest in detailed seedling analysis comprising whole seedlings, shoots, roots, and root tips. To quantify transcript levels in reproductive tissues, we included five pollen developmental stages (uninucleate microspores, early bicellular pollen, late bicellular pollen, immature tricellular pollen, and mature pollen). We observed $A R M$ transcripts in all tissues tested. The relative transcriptional level of $A R M$ was 100 times higher than that

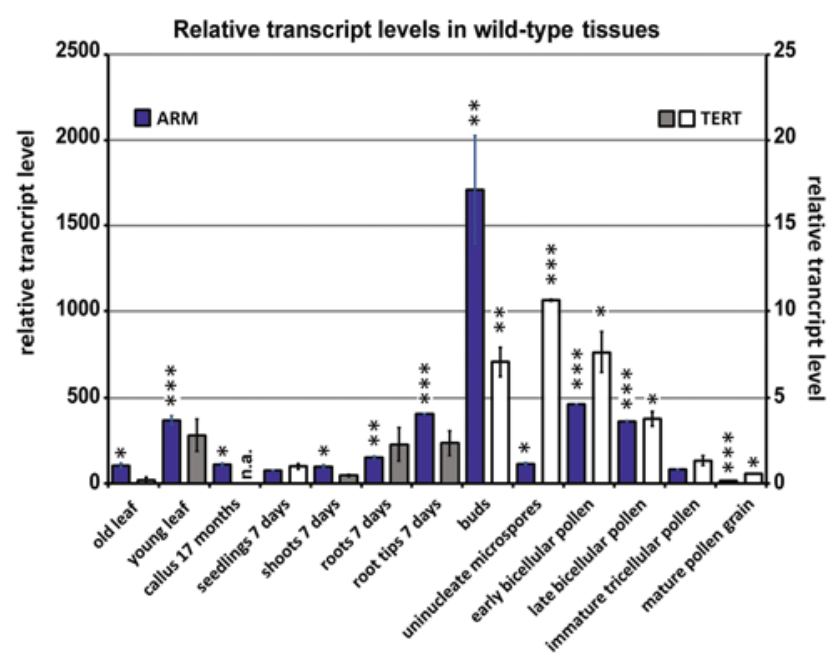

Fig. 2 Analyses of ARM and AtTERT gene expression in wild-type plants. Transcript levels of ARM (left y-axis) and AtTERT (right $\mathrm{y}$-axis) genes in various wild-type plant tissues and developmental stages were calculated relative to AtTERT levels in 7-day-old seedlings (Col-0) arbitrarily set to 1 . AtTERT levels were compiled from our experimental data (white columns) or adapted from previous work (columns in grey; Ogrocka et al. 2012-young and old leaf; and Zachova et al. 2013-shoots, roots and root tips of 7-day seedlings). $\mathrm{P}$ values are shown for the ARM and AtTERT gene levels as experimentally determined here. Experiments were performed as three biological replicas except the pollen samples that were repeated twice 
of AtTERT and gene transcript profiles partially overlapped (Fig. 2). ARM transcripts were abundant in proliferating tissues that were telomerase positive-flower buds, young leaves, roots - and were slightly elevated during two stages of pollen development corresponding to proliferative activity. A detailed comparison of ARM and AtTERT transcriptional profiles in 7-day-old seedlings revealed co-expression of both genes in root tips. In contrast to ARM, the AtTERT gene showed high transcript levels in early stages of pollen development. High levels of $A R M$ transcripts that were detected in flower buds might be connected with high proliferative activity within floral meristems and in reproductive tissues of both sporophytic and female gametophytic origins as we did not observe a corresponding increase in ARM transcripts in various developmental stages of pollen.

\section{Telomere length and telomerase activity are not affected in homozygous arm mutants}

To examine the role of ARM in planta, we analyzed homozygous Arabidopsis T-DNA insertion lines SALK_063839C (arm-1, intron 2) and SALK_150486C (arm-2, intron 1) (Fig. 3a). RT-qPCR results using exon 6- and 7-specific primers confirmed only arm-1 as a null allele, whereas the arm-2 allele caused only a partial decrease $(\sim 50 \%)$ in the level of the ARM transcript when compared to Col-0 wild-type plants (Fig. 3b). Sequencing of the RT-PCR product overlapping the T-DNA insertion site in arm-2 mutants revealed that the T-DNA was spliced out, resulting in a correct splice junction. Both arm lines displayed normal vegetative growth and no detectable morphological differences were observed compared to soil-grown wild-type (Col-0) plants in three subsequent generations of homozygous arm-/- mutants (Supplemental Fig. S3, see Supplemental material for details).

To investigate the telomere phenotype we analyzed telomere length in the third generation (G3) of homozygous mutant plants using terminal restriction fragment (TRF) analysis. Although telomeres in both arm-1/arm-1 and arm-2/arm-2 G3 plants were slightly longer when compared to those of wild-type plants (Supplemental Fig. S4), a paired Student t-test indicated that these changes were not significant (the two-tailed $\mathrm{P}$ values equal 0.1175 and 0.0751 for $a r m-1$ and $a r m-2$, respectively). Telomerase activity was tested in 7-day-old seedlings of the G3 generation of homozygous arm-1 and arm-2 lines using a telomere repeat amplification protocol (TRAP). No changes in telomerase activity were observed using the conventional or quantitative TRAP assays (Supplemental Fig. S5). These results suggest that ARM is not essential for maintaining telomere length and telomerase activity.

\section{ARM may be involved in translation initiation}

We and other groups (Dokladal et al. 2015; Schrumpfova et al. 2016; Zhou et al. 2016) recently suggested that

(A)

(B)
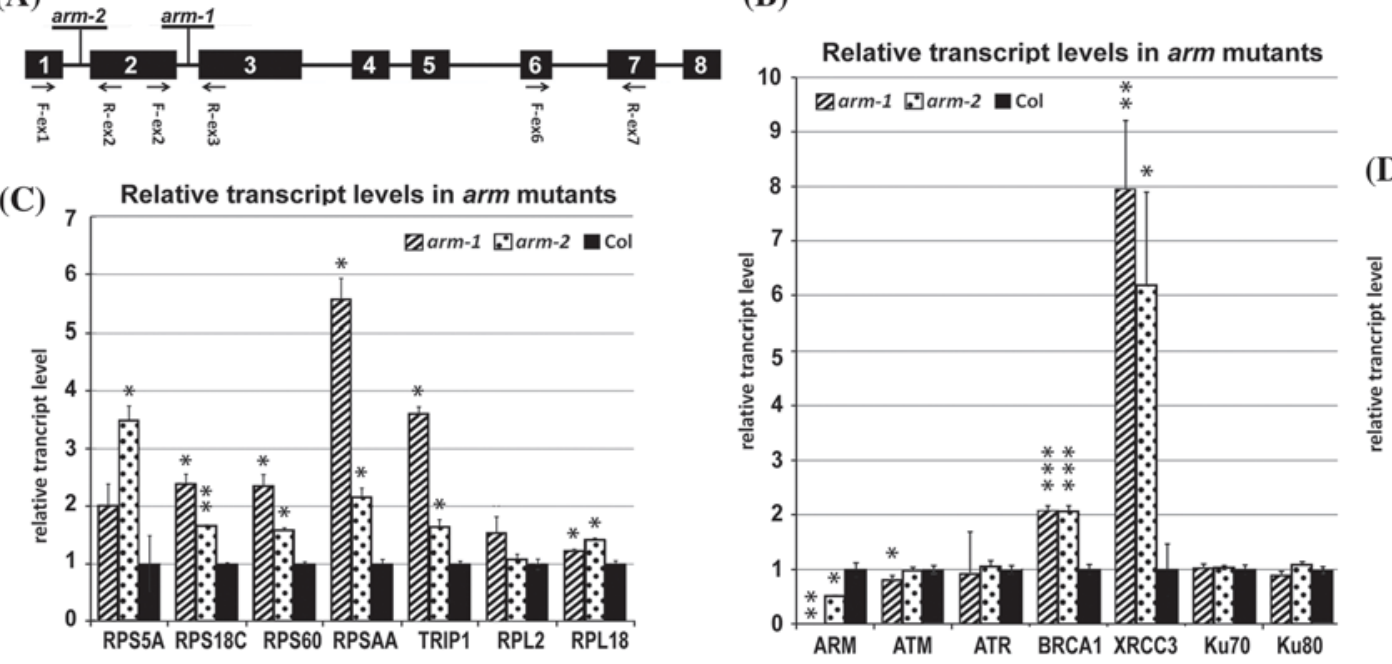

(D)

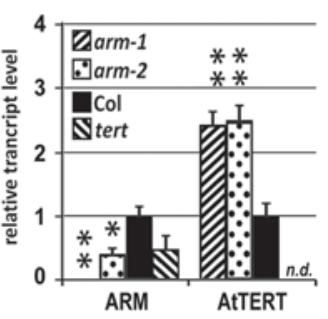

Fig. 3 Analyses of gene expression in mutant plants. a Position of the T-DNA insertions within the $A R M$ gene and primer sites used for genotyping and RT-qPCR are shown. b Transcript levels of genes involved in DNA repair, and c ribosomal protein and translationrelated genes were affected in the arm-1 and arm-2 T-DNA insertion lines. d Transcript levels of AtTERT were increased in arm-1 and arm-2 lines, and transcript levels of the $A R M$ gene were decreased in a tert mutant. The level of transcripts of indicated genes (b-d) were calculated relative to those in wild-type $(\mathrm{Col}-0)$ leaves $(\mathbf{b}, \mathbf{c})$ or 7-dayold seedlings (d) using the $\Delta \Delta \mathrm{Ct}$ method and $u b i 10$ as a reference gene. Relative transcript levels were calculated as a median of transcript levels; two-tailed $\mathrm{P}$ values were calculated using an unpaired t-test $(* \mathrm{p}<0.05 ; * * \mathrm{p}<0.001 ; * * * \mathrm{p}=0.0001)$. n.d. not detected 
Arabidopsis telomerase and its interacting partners, the RRM and the SMH family protein AtTRB1, may be involved in the regulation of ribosomal and translation-related genes. However, data from tert-/- mutants (Amiard et al. 2014) showed no changes in transcript levels of ribosomal protein genes. To test a possible involvement of ARM protein in these processes, we measured transcript levels of selected representatives of ribosomal protein genes, that were upregulated in $\mathrm{rrm}$ mutants (Dokladal et al. 2015), in arm mutant lines (Fig. 3c). We found significant changes in transcript abundance of four genes encoding components of the small ribosomal subunit (RPS5A, RPS18C, RPS60 and RPSAA): a two to sixfold increase in transcript levels in the arm-1 line. RPS5A and RPSAA also showed a greater than twofold increase in transcript levels in the arm-2 line. Genes encoding components of the large ribosomal subunit (RPL2, $R P L 18$ ) displayed less than a twofold increase in transcript levels in mutant plants. We further analyzed transcript abundance of the translation initiation factor TRIP1 (TGF-beta receptor interacting protein 1 ) encoding a component of the 43S preinitiation complex. A greater than threefold increase in TRIPI transcript levels was detected in the arm-l line, supporting a possible link between ARM and the formation of a translation preinitiation complex.

To investigate a possible involvement of the ARM protein in the regulation of translation-related genes, we further tested the putative promoter of the RPSAA gene that showed the highest transcriptional increase in the arm-1 line. We fused the firefly luciferase (fluc) coding sequence with sequences 500 or $1000 \mathrm{bp}$ upstream from the translation start of RPSAA and co-transfected these reporter constructs, with either a 35S::ARM effector construct or with a 35S::GUS reference construct, into Arabidopsis protoplasts. Firefly luciferase expression was decreased by the $35 \mathrm{~S}:$ :ARM effector construct in protoplasts co-transfected with RPSAA1000::fluc but not with the RPSAA-500::fluc reporter construct (Fig. 4). Thus, the RPSAA sequence $1000 \mathrm{bp}$ upstream from the translation start seemed to be necessary to affect transcription.

\section{ARM is involved in regulation of recombination-related genes}

A direct link between telomerase activity and DNA repair pathways has not yet been established. However, these processes coexist, e.g. during chromosomal healing in response to DNA damage (Fojtova et al. 2002; Jankowska et al. 2015). Once a double-stranded break (DSB) occurs, the cell must choose between homologous recombination (HR) and nonhomologous end joining (NHEJ) to fix the break. These pathways are often in competition with each other. However, natural HR occurs during DNA replication (S phase of the cell cycle) and established models for alternative

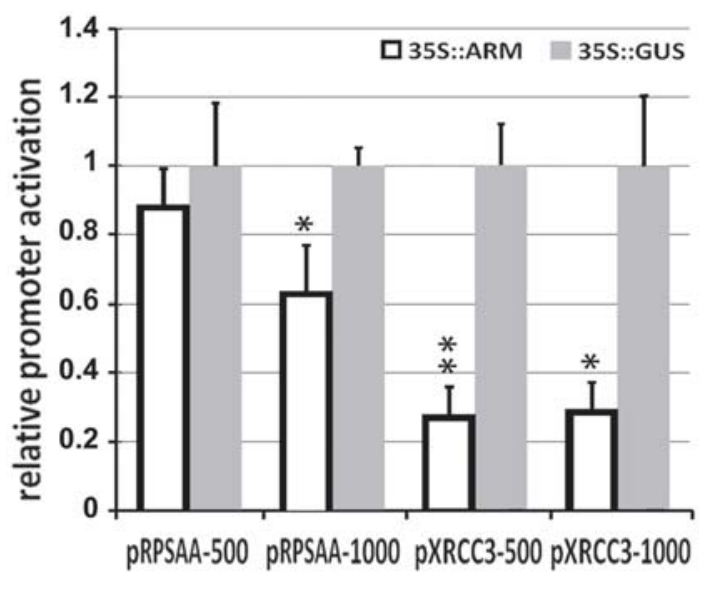

Fig. 4 ARM overexpression effects on XRCC3 and RPSAA promoter activation. Luciferase reporter assay shows that expression of the 35S::ARM ("effector") construct decreases expression of RPSAA and $X R C C 3$ promoter ("reporter") constructs. Sequences 500 and 1000 bp upstream from the translation start fused with firefly luciferase were sufficient in the case of $X R C C 3$ and RPSAA, respectively. A $35 \mathrm{~S}:$ GUS construct was used as a reference. Arabidopsis protoplasts were transfected with reporter and effector/reference-encoding plasmids and with a plasmid encoding Renilla luciferase that serves as a normalization control. Both firefly (fluc) and Renilla (rluc) luciferase activities were measured $16 \mathrm{~h}$ after transfection. Relative promoter activation was calculated as (fluc/rluc) $)_{\text {effector }}$ (fluc/rluc) $)_{\text {reference }}$ Twotailed $\mathrm{P}$ values were calculated using an unpaired t-test $(* \mathrm{p}<0.05$; $* * \mathrm{p}<0.001)$

lengthening of telomeres also include the HR pathway (see Pickett and Reddel 2015; Trapp et al. 2011, for review). It is not clear whether plant telomerase and DNA repair proteins are collaborators or antagonists, or at what level their actions are regulated. We therefore analyzed the transcript accumulation profiles of key DSB repair genes, ATM and $A T R$, and representative genes related to both major DSB repair pathways in homozygous arm-1 and arm-2 mutant lines. ATM, ATR, $K u 70$, and $K u 80$, genes with established functions in telomere homeostasis and NHEJ (Amiard et al. 2011), did not show greater than twofold change in relative transcript abundance in mutant compared to that of wildtype plants (Fig. 3b, Supplemental Table S3). Transcript levels of $B R C A 1$ and $X R C C 3$, factors involved in HR (see Trapp et al. 2011; Yoshiyama et al. 2013, for review), were significantly higher in both arm T-DNA insertion lines (Fig. 3b), suggesting a possible role of ARM in the regulation of HRrelated genes. Interestingly, $X R C C 3$ transcripts were greatly increased in young leaves, but not in buds and seedlings of arm-1 mutants (Table 1, Supplemental Table S3). To investigate direct involvement of the ARM protein in transcriptional regulation of the $X R C C 3$ gene, we performed a transient expression assay using luciferase expression vectors. Reporter constructs with the firefly luciferase coding sequence fused with sequences 500 or $1000 \mathrm{bp}$ upstream from translation start of $X R C C 3$ were co-transfected either 
Table 1 Relative transcription levels of homologous recombination-related genes affected in homozygous arm mutants

\begin{tabular}{|c|c|c|c|c|c|c|c|}
\hline \multirow[t]{3}{*}{ AGI number } & \multirow[t]{3}{*}{ Gene name } & \multicolumn{4}{|c|}{ Leaves $^{\mathrm{a}}$} & \multirow{2}{*}{\multicolumn{2}{|c|}{$\frac{\text { Buds }^{\mathrm{a}}}{\text { arm-1 }}$}} \\
\hline & & \multicolumn{2}{|l|}{ arm-1 } & \multicolumn{2}{|l|}{ arm-2 } & & \\
\hline & & $2^{-\mathrm{ddCt}}$ & SD & $2^{-\mathrm{ddCt}}$ & SD & $2^{-\mathrm{ddCt}}$ & SD \\
\hline \multicolumn{8}{|c|}{ DNA damage complex III } \\
\hline AT4G21070 & BRCA1 & 2.09 & 0.09 & 2.08 & 0.09 & 0.88 & 0.11 \\
\hline \multicolumn{8}{|c|}{ RecA/RAD51 family } \\
\hline AT2G19490 & $\operatorname{Rec} A(2)$ & 2.47 & 0.09 & 2.66 & 0.30 & 0.77 & 0.08 \\
\hline AT3G10140 & $\operatorname{RecA}(3)$ & 2.02 & 0.11 & 2.05 & 0.07 & 0.98 & 0.08 \\
\hline AT5G20850 & RAD51 & 0.47 & 0.07 & 0.79 & 0.17 & 0.44 & 0.05 \\
\hline AT2G28560 & RAD51B & 3.05 & 0.40 & 3.86 & 0.16 & 0.62 & 0.03 \\
\hline AT2G45280 & RAD51C & 2.08 & 0.24 & 2.60 & 0.28 & 0.39 & 0.01 \\
\hline AT3G22880 & DMC & 2.11 & 0.18 & 1.56 & 0.04 & 0.44 & 0.14 \\
\hline AT5G57450 & XRCC3 & 7.96 & 1.25 & 6.20 & 1.7 & 0.94 & 0.14 \\
\hline \multicolumn{8}{|c|}{ MUS81-EME1 complex } \\
\hline AT2G21800 & EME1(A) & 2.80 & 0.36 & 3.21 & 0.06 & 2.35 & 0.15 \\
\hline \multicolumn{8}{|c|}{ Single strand DNA binding } \\
\hline AT4G11060 & MTSSB & 2.00 & 0.21 & 2.70 & 0.25 & 0.59 & 0.15 \\
\hline AT3G18580 & SSB & 2.15 & 0.13 & 2.31 & 0.13 & 1.61 & 0.11 \\
\hline \multicolumn{8}{|l|}{ DNA helicases } \\
\hline AT2G01440 & RecG & 2.01 & 0.12 & 1.82 & 0.06 & 1.71 & 0.16 \\
\hline
\end{tabular}

with the $35 S:: A R M$ effector or the $35 S:: G U S$ reference constructs into Arabidopsis protoplasts. Calculation of relative promoter activation clearly demonstrated that the XRCC3 reporters were down-regulated when ARM was overexpressed, and sequences within $500 \mathrm{bp}$ upstream from the translation start of $X R C C 3$ were sufficient for this suppression (Fig. 4). We therefore focused further experiments on mRNA abundance of Arabidopsis HR-related genes (Singh et al. 2010). In total, nine genes displayed a greater than twofold increase in transcript levels in both mutant lines, and two additional genes showed increased transcript abundance only in the homozygous arm-1 line (Table 1). Affected genes were found among members of the RecA/RAD51 family, genes for ssDNA binding proteins, and the MUS81-EME1 resolvase complex. Interestingly, in contrast to RAD51 paralogs that function as recombination mediators, the level of recombinase RAD51 transcripts was significantly decreased in leaves and buds but not in seedlings of the homozygous arm- 1 line (Table 1, Supplemental Table S3). Several affected genes are also important for mitochondrial DNA repair, but transcript levels of other genes from these pathways were not changed in arm-1 mutants (Supplemental Table S3). In addition, we observed that AtTERT transcript levels were not affected in young leaves and buds. However a $>$ twofold increase was detected in seedlings of the arm-1 mutant line (Fig. 3d, Supplemental Table S3). No significant change in ARM transcript levels was detected in seedlings of tert-/- plants (Fig. 3d), which is in agreement with microarray data of Amiard et al. (2014). In conclusion, transcript levels of AtTERT and of several other genes involved in the HR pathway were affected in arm mutants, suggesting involvement of ARM in their transcriptional or posttranscriptional regulation.

\section{ARMC6 binds TRF2 and human telomerase}

Searching for Arabidopsis ARM protein functions, we analyzed its putative human homolog ARMC6. To test putative interactions of ARMC6 with other proteins, we ran pilot experiments in vitro. We detected weak positive protein-protein interactions between TRF2 and ARMC6 (Supplemental Fig. S6a). Expression of ARMC6 protein in a rabbit reticulocyte lysate (RRL) system was low. However, we observed the same result using an ARMC6 construct cloned into two different vectors (pTriEx4 and pDEST17). Arabidopsis ARM protein interacts with AtTERT. Thus, we investigated if ARMC6 was able to interact with human telomerase. We reconstituted telomerase activity using constructs of hTERT and hTR (Bachand et al. 2000) expressed in a RRL. The c-myc tagged construct of ARMC6 was able to immunoprecipitate telomerase activity (Supplemental Fig. S6b). The same result was observed for TPP1 protein that is a known interactor with hTERT (Zaug et al. 2010) and was used as a positive control. Whether these results indicate a functional 
similarity between human and plant ARM proteins needs further investigation.

\section{Discussion}

Plant ARM repeat proteins represent a functionally heterogeneous group, formally unified only by the presence of armadillo/ $\beta$-catenin-like repeats serving as protein-protein interaction domains (see Tewari et al. 2010, and references therein). Our original hypothesis about putative involvement of Arabidopsis ARM protein in non-telomeric functions of telomerase (Lee et al. 2012) was inspired by the human model. hTERT forms a transcription regulatory complex with $\beta$-catenin and a chromatin remodeling factor BRG1, thereby providing a link to the Wnt signaling pathway (Park et al. 2009). The putative Arabidopsis homolog of BRG1 is the Snf2-like ATPase chromatin remodeling 12 (CHR12) (see Dona and Mittelsten Scheid 2015 for review). Unfortunately, we could not test its protein-protein interactions because CHR12 (1102 amino acids) was not expressed either in the $\mathrm{Y} 2 \mathrm{H}$ or BiFC systems (not shown). Animal catenins can localize at the plasma membrane, where they bind the cytoplasmic tail of cadherin (Aberle et al. 1994; Ozawa et al. $1989)$, and in the nucleus, where $\beta$-catenin can affect expression of Wnt target genes (Behrens 2000). Cytosolic $\beta$-catenin must be stabilized by the concerted action of several kinases and scaffold proteins before it enters the nucleus (see Coates 2003; Tewari et al. 2010, for review). We observed that GFP-ARM protein localizes in the nucleus, cytoplasm, and plasma membrane of plant cells (Fig. 1c, Supplemental Fig. S2). We do not know whether the Arabidopsis ARM protein needs specific modifications before it can enter the nucleus; however, variable ARM localization may indicate a multifunctional role such as that shown by human $\beta$-catenin. Posttranslational modifications of the ARM protein may also explain the discrepancy between the negative co-IP result and the positive BiFC result for ARM-TRFL9 interaction. Interestingly, pollen-specific Arabidopsis Armadillo Repeat Only 1 (ARO1) protein, that regulates cell growth and actin organisation, also shows a sub-cellular localization similar to that of $\beta$-catenin (Gebert et al. 2008).

We have previously characterized the interaction between the ARM protein and the CTE domain of AtTERT predominantly in the cytoplasm of tobacco BY-2 protoplasts (Lee et al. 2012). Here we further investigated protein-protein interactions and determined the telomere phenotype using arm T-DNA insertion mutant lines (Supplemental Fig. S4). Our analyses showed no significant changes in telomere lengths and telomerase activity, suggesting that the ARM protein is not essential for telomere maintenance, and that the observed interaction with telomerase may reflect possible non-telomeric functions. Tissue-specific $A R M$ expression correlates partially with that of AtTERT (Fig. 2). Thus, while investigating further possible telomerase-linked roles of ARM, we focused on (i) protein-protein interactions with proteins identified previously as telomere/telomerase interactors in vivo and in vitro and (ii) mRNA levels of genes presumably affected in arm mutants. We demonstrated that ARM interacts with TRF-like family I proteins and the chromatin remodeling protein CHR19 both in yeast and in planta. The protein parts of Arabidopsis telomerase holoenzyme, AtTERT and POT1a, interact with CHR19, members of the TRF-like family I proteins, and with SMH proteins (summarized on Fig. 1f). Interestingly, ARM, TRB1, and CHR19 (but none of the TRF-like family I proteins) were found among proteins that co-purified with Arabidopsis TERT and POT1a using tandem affinity purification (Majerska et al. 2017). These interactions further link telomerase and ARM with transcriptional regulation because of reported functions of chromatin modulators for $\mathrm{SMH}$ proteins and chromatin remodeling protein CHR19 (see Dona and Mittelsten Scheid 2015; Prochazkova Schrumpfova et al. 2016, for review). In addition to a transcriptional regulation function, putative mammalian/yeast homologs of CHR19 promote DNA end resection (Costelloe et al. 2012), the first step common to all homologous recombination repair reactions. Thus, it is tempting to speculate that AtTERT-CHR19 and/or TRB1-CHR19 interactions might be important, e.g., for telomere repeat addition de novo. In conclusion, dual functions reported for the interaction partners of ARM and/or AtTERT in telomere maintenance and transcriptional regulation support the hypothesis establishing an interaction network of ARM, AtTERT, POT1a, and other proteins (Fig. 1f) involved in non-telomeric pathways, but this requires further investigation.

It is unclear which of the human armadillo proteins represents a functional homolog of the Arabidopsis ARM protein. Human $\beta$-catenin contains twelve armadillo repeats and it has been suggested that, with the exception of glycogen synthase kinase-3 (GSK-3) that destabilizes cytosolic $\beta$-catenin, there are no Wnt signaling pathway homologues in Arabidopsis (Jonak and Hirt 2002). Moreover, we identified a putative human homolog, ARMC6, containing four armadillo repeats (accession Q6NXE6, http://www.unipr ot.org), among proteins co-purified with the human shelterin protein TRF2 (Giannone et al. 2010). ARMC6 protein does not have any known biological function and its interaction with hTRF2 has not been tested. Putative homologs of ARMC6 were predicted in silico in evolutionarily diverse groups including animals, plants, green algae, chromalveolates and excavates, but not in fungi (see Tewari et al. 2010 for review). In our pilot study (see Supplemental Material for details), we confirmed an interaction between TRF2 and ARMC6 in vitro (Supplemental Fig. S6A). ARMC6 protein also pulls-down human telomerase reconstituted 
in vitro (Supplemental Fig. S6B), resembling the Arabidopsis ARM-TERT interaction described here. It remains to be shown whether there are any additional biochemical or functional similarities among these putative Arabidopsis and human homologs.

Non-telomeric functions of telomerase in animals are mediated by TERT-dependent alteration of gene expression (reviewed in Majerska et al. 2011). In the search for ARM biological functions and possible non-telomeric functions of AtTERT, we investigated the mRNA levels of several gene groups in arm mutants. Initially, we tested genes with telobox-containing promoters because binding to such genomic loci was demonstrated for SMH proteins (Schrumpfova et al. 2016; Zhou et al. 2016), and also because TRF-like family I proteins can bind telomeric repeats in vitro, similarly to SMH proteins (Karamysheva et al. 2004; Schrumpfova et al. 2004). Increased mRNA levels of ribosomal genes under the control of telobox-containing promoters were also observed in mutant lines with a disrupted $R R M$ gene that encodes another AtTERT-interacting protein (Dokladal et al. 2015). We observed significant changes in transcription of some (but not all) ribosomal genes under the control of teloboxcontaining promoters in arm-1 and arm-2 T-DNA insertion lines (Fig. 3c). Affected genes represented a subset of those encoding proteins involved in the formation of a translation preinitiation complex, and we detected down-regulation of the putative promoter of the RPSAA gene, suggesting that ARM can modulate its expression in plant cells. In the particular case of the RPSAA promoter, the telobox-like sequence is present within the $500 \mathrm{bp}$ sequence that was not affected by ARM (Fig. 4). These results also show that the presence of the telobox regulatory motif is not a critical determinant for specific gene expression, confirming results of previous studies (Dokladal et al. 2015; Regad et al. 1994; Schrumpfova et al. 2016; Tremousaygue et al. 2003; Zhou et al. 2016). Secondly, we investigated genes involved in DNA repair pathways and found significant changes in expression of HR-related genes (Fig. 3b; Table 1). Analyses of gene expression in arm mutant plants showed that most genes influenced by disruption of the $A R M$ gene were upregulated in leaves, the $X R C C 3$ gene being the most affected one (Table 1). However, the same genes were down-regulated or not affected in floral buds (Supplemental Table S3), a complex tissue with the highest natural levels of $A R M$ and AtTERT transcripts (Fig. 2), indicating more complex or specialized roles of ARM in a tissue-specific manner. The only exception was a gene encoding EME1a, part of the MUS81EME1 resolvase recognizing specific Holliday-junction structures (Geuting et al. 2009), which was similarly upregulated in leaves and buds of arm mutants (Table 1). Investigation of other genes implicated in specific meiotic functions showed that in some cases, only mild deregulation occurred in buds (Supplemental Table S3). This observation awaits further study. It should be noted that telomeres were slightly longer in arm mutants. Thus, we cannot exclude the possibility that slight defects in telomere length might be sufficient to induce expression of HR-related genes. A putative ARM function as a transcriptional repressor was supported by our results demonstrating down-regulation of the $X R C C 3$ promoter construct in a luciferase assay in Arabidopsis protoplasts (Fig. 4). We speculate that the downregulation of the RPSAA and $X R C C 3$ promoter constructs most likely depends on ARM recognition of some additional DNA binding factor(s) and recruitment of a transcription repressor(s). These factors could represent completely different subsets of transcriptional regulators, including those unrelated to telomerase or TRB/TRFL-I proteins.

In conclusion, our results suggest that ARM can function as a modulator of gene expression, possibly through its interaction with nuclear proteins involved in transcriptional regulation. Thus, we suggest that ARM can participate in non-telomeric functions of telomerase, and can also perform its own telomerase-independent functions.

Acknowledgements We would like to thank our colleagues Jiří Fajkus and Miloslava Fojtová (Institute of Biophysics, Czech Republic) for helpful comments on the manuscript draft, Andrej Hurný (IST Austria) for help with the luciferase reporter assay, Chantal Autexier (McGill University, Montreal, Quebec, Canada) and Ctirad Hofr (Masaryk University Brno, Czech Republic) for human protein constructs, Jan Paleček (Masaryk University Brno, Czech Republic) for vectors, and Bořivoj Vojtěšek (Masaryk University Brno, Czech Republic) for antiHA antibodies. This work was supported by the Grant Agency of the Czech Republic (18-07027S) and by institutional support.

Author contributions LD performed experiments except RT-qPCR analysis of pollen samples (ND and DH), EB contributed in phenotype analyses, ES analysed data, L-YL and SG were involved in ARM localization experiments, SG and ES designed study, LD, SG and ES wrote the paper.

\section{Compliance with ethical standards}

Conflict of interest The authors have no conflict of interest to declare.

\section{References}

Aberle H, Butz S, Stappert J, Weissig H, Kemler R, Hoschuetzky H (1994) Assembly of the cadherin-catenin complex in vitro with recombinant proteins. J Cell Sci 107(Pt 12):3655-3663

Alonso JM et al (2003) Genome-wide insertional mutagenesis of Arabidopsis thaliana. Science 301:653-657

Amiard S, White C, Gallego ME (2011) Recombination proteins and telomere stability in plants. Curr Protein Pept Sci 12:84-92

Amiard S, Da Ines O, Gallego ME, White CI (2014) Responses to telomere erosion in plants. PLoS ONE 9:e86220. https://doi. org/10.1371/journal.pone.0086220

Bachand F, Kukolj G, Autexier C (2000) Expression of hTERT and hTR in cis reconstitutes and active human telomerase ribonucleoprotein. RNA 6:778-784 
Behrens J (2000) Control of beta-catenin signaling in tumor development. Ann N Y Acad Sci 910:21-33

Blasco MA (2005) Mice with bad ends: mouse models for the study of telomeres and telomerase in cancer and aging. EMBO J 24:10951103. https://doi.org/10.1038/sj.emboj.7600598

Broccoli D, Smogorzewska A, Chong L, de Lange T (1997) Human telomeres contain two distinct Myb-related proteins, TRF1 and TRF2. Nat Genet 17:231-235. https://doi.org/10.1038/ng109 7-231

Chong L, van Steensel B, Broccoli D, Erdjument-Bromage H, Hanish J, Tempst P, de Lange T (1995) A human telomeric protein. Science 270:1663-1667

Citovsky V et al (2006) Subcellular localization of interacting proteins by bimolecular fluorescence complementation in planta. J Mol Biol 362:1120-1131. https://doi.org/10.1016/j.jmb.2006.08.017

Coates JC (2003) Armadillo repeat proteins: beyond the animal kingdom. Trends Cell Biol 13:463-471

Collins K (2006) The biogenesis and regulation of telomerase holoenzymes. Nat Rev Mol Cell Biol 7:484-494. https://doi.org/10.1038/ nrm1961

Costelloe T et al (2012) The yeast Fun30 and human SMARCAD1 chromatin remodellers promote DNA end resection. Nature 489:581-584. https://doi.org/10.1038/nature11353

Culligan KM, Robertson CE, Foreman J, Doerner P, Britt AB (2006) ATR and ATM play both distinct and additive roles in response to ionizing radiation. Plant J 48:947-961. https://doi.org/10.1111/ j.1365-313X.2006.02931.x

da Costa e Silva O, Klein L, Schmelzer E, Trezzini GF, Hahlbrock K (1993) BPF-1, a pathogen-induced DNA-binding protein involved in the plant defense response. Plant J 4:125-135

de Lange T (2005) Shelterin: the protein complex that shapes and safeguards human telomeres. Genes Dev 19:2100-2110. https://doi. org/10.1101/gad.1346005

Dokladal L, Honys D, Rana R, Lee LY, Gelvin SB, Sykorova E (2015) cDNA library screening identifies protein interactors potentially involved in non-telomeric roles of arabidopsis telomerase. Front Plant Sci 6:985. https://doi.org/10.3389/fpls.2015.00985

Dona M, Mittelsten Scheid O (2015) DNA damage repair in the context of plant chromatin. Plant Physiol 168:1206-1218. https://doi. org/10.1104/pp.15.00538

Dupl'akova N, Dobrev PI, Renak D, Honys D (2016) Rapid separation of Arabidopsis male gametophyte developmental stages using a Percoll gradient. Nat Protoc 11:1817-1832. https://doi. org/10.1038/nprot.2016.107

Duplakova N, Renak D, Hovanec P, Honysova B, Twell D, Honys D (2007) Arabidopsis gene family profiler (aGFP)—user-oriented transcriptomic database with easy-to-use graphic interface. BMC Plant Biol 7:39. https://doi.org/10.1186/1471-2229-7-39

Dvorackova M, Fojtova M, Fajkus J (2015) Chromatin dynamics of plant telomeres and ribosomal genes. Plant J 83:18-37. https:// doi.org/10.1111/tpj.12822

Fajkus J, Kovarik A, Kralovics R (1996) Telomerase activity in plant cells. FEBS Lett 391:307-309

Fitzgerald MS, McKnight TD, Shippen DE (1996) Characterization and developmental patterns of telomerase expression in plants. Proc Natl Acad Sci USA 93:14422-14427

Fojtova M, Fulneckova J, Fajkus J, Kovarik A (2002) Recovery of tobacco cells from cadmium stress is accompanied by DNA repair and increased telomerase activity. J Exp Bot 53:2151-2158

Fojtova M, Peska V, Dobsakova Z, Mozgova I, Fajkus J, Sykorova E (2011) Molecular analysis of T-DNA insertion mutants identified putative regulatory elements in the AtTERT gene. J Exp Bot 62:5531-5545. https://doi.org/10.1093/jxb/err235

Fulcher N, Riha K (2015) Using centromere mediated genome elimination to elucidate the functional redundancy of candidate telomere binding proteins in Arabidopsis thaliana. Front Genet 6:349. https ://doi.org/10.3389/fgene.2015.00349

Gebert M, Dresselhaus T, Sprunck S (2008) F-actin organization and pollen tube tip growth in Arabidopsis are dependent on the gametophyte-specific Armadillo repeat protein ARO1. Plant Cell 20:2798-2814. https://doi.org/10.1105/tpc.108.061028

Geuting V, Kobbe D, Hartung F, Durr J, Focke M, Puchta H (2009) Two distinct MUS81-EME1 complexes from Arabidopsis process Holliday junctions. Plant Physiol 150:1062-1071. https:// doi.org/10.1104/pp.109.136846

Giannone RJ, McDonald HW, Hurst GB, Shen RF, Wang Y, Liu Y (2010) The protein network surrounding the human telomere repeat binding factors TRF1, TRF2, and POT1. PLoS ONE 5:e12407. https://doi.org/10.1371/journal.pone.0012407

Gohring J, Fulcher N, Jacak J, Riha K (2014) TeloTool: a new tool for telomere length measurement from terminal restriction fragment analysis with improved probe intensity correction. Nucleic Acids Res 42:e21. https://doi.org/10.1093/nar/gkt1315

Greider CW, Blackburn EH (1985) Identification of a specific telomere terminal transferase activity in Tetrahymena extracts. Cell 43:405-413

Greider CW, Blackburn EH (1987) The telomere terminal transferase of Tetrahymena is a ribonucleoprotein enzyme with two kinds of primer specificity. Cell 51:887-898

Heinekamp T, Kuhlmann M, Lenk A, Strathmann A, Droge-Laser W (2002) The tobacco bZIP transcription factor BZI-1 binds to G-box elements in the promoters of phenylpropanoid pathway genes in vitro, but it is not involved in their regulation in vivo. Mol Genet Genomics 267:16-26. https://doi.org/10.1007/s0043 8-001-0636-3

Jankowska M et al (2015) Holokinetic centromeres and efficient telomere healing enable rapid karyotype evolution. Chromosoma 124:519-528. https://doi.org/10.1007/s00412-015-0524-y

Janouskova E et al (2015) Human Rap1 modulates TRF2 attraction to telomeric DNA. Nucleic Acids Res 43:2691-2700. https://doi. org/10.1093/nar/gkv097

Jonak C, Hirt H (2002) Glycogen synthase kinase 3/SHAGGY-like kinases in plants: an emerging family with novel functions. Trends Plant Sci 7:457-461

Karamysheva ZN, Surovtseva YV, Vespa L, Shakirov EV, Shippen DE (2004) A C-terminal Myb extension domain defines a novel family of double-strand telomeric DNA-binding proteins in Arabidopsis. J Biol Chem 279:47799-47807. https://doi.org/10.1074/ jbc.M407938200

Kuchar M, Fajkus J (2004) Interactions of putative telomere-binding proteins in Arabidopsis thaliana: identification of functional TRF2 homolog in plants. FEBS Lett 578:311-315. https://doi. org/10.1016/j.febslet.2004.11.021

Lee LY et al (2012) Screening a cDNA library for protein-protein interactions directly in planta. Plant Cell 24:1746-1759. https://doi. org/10.1105/tpc. 112.097998

Lugert T, Werr W (1994) A novel DNA-binding domain in the Shrunken initiator-binding protein (IBP1). Plant Mol Biol 25:493-506

Majerska J, Sykorova E, Fajkus J (2011) Non-telomeric activities of telomerase. Mol Biosyst 7:1013-1023. https://doi.org/10.1039/ $\mathrm{c} 0 \mathrm{mb} 00268 \mathrm{~b}$

Majerska J et al (2017) Tandem affinity purification of AtTERT reveals putative interaction partners of plant telomerase in vivo. Protoplasma 254:1547-1562. https://doi.org/10.1007/s0070 9-016-1042-3

Nagaoka S, Takano T (2003) Salt tolerance-related protein STO binds to a Myb transcription factor homologue and confers salt tolerance in Arabidopsis. J Exp Bot 54:2231-2237. https://doi.org/10.1093/ jxb/erg241 
Nelson BK, Cai X, Nebenfuhr A (2007) A multicolored set of in vivo organelle markers for co-localization studies in Arabidopsis and other plants. Plant J 51:1126-1136. https://doi.org/10.1111/ j.1365-313X.2007.03212.x

Ogrocka A, Sykorova E, Fajkus J, Fojtova M (2012) Developmental silencing of the AtTERT gene is associated with increased H3K27me3 loading and maintenance of its euchromatic environment. J Exp Bot 63:4233-4241. https://doi.org/10.1093/jxb/ers107

Ozawa M, Baribault H, Kemler R (1989) The cytoplasmic domain of the cell adhesion molecule uvomorulin associates with three independent proteins structurally related in different species. EMBO J 8:1711-1717

Park JI et al (2009) Telomerase modulates Wnt signalling by association with target gene chromatin. Nature 460:66-72. https://doi. org/10.1038/nature08137

Pfaffl MW (2004) Quantification strategies in real-time PCR. In: Bustin SA (ed) A-Z of quantitative PCR. International University Line, La Jolla, CA, pp 87-112

Pickett HA, Reddel RR (2015) Molecular mechanisms of activity and derepression of alternative lengthening of telomeres. Nat Struct Mol Biol 22:875-880. https://doi.org/10.1038/nsmb.3106

Prochazkova Schrumpfova P, Schorova S, Fajkus J (2016) Telomere- and telomerase-associated proteins and their functions in the plant cell. Front Plant Sci 7:851. https://doi.org/10.3389/ fpls.2016.00851

Regad F, Lebas M, Lescure B (1994) Interstitial telomeric repeats within the Arabidopsis thaliana genome. J Mol Biol 239:163-169. https://doi.org/10.1006/jmbi.1994.1360

Rossignol P, Collier S, Bush M, Shaw P, Doonan JH (2007) Arabidopsis POT1A interacts with TERT-V(I8), an N-terminal splicing variant of telomerase. J Cell Sci 120:3678-3687. https://doi. org/10.1242/jcs.004119

Schrumpfova P, Kuchar M, Mikova G, Skrisovska L, Kubicarova T, Fajkus J (2004) Characterization of two Arabidopsis thaliana myb-like proteins showing affinity to telomeric DNA sequence. Genome 47:316-324. https://doi.org/10.1139/g03-136

Schrumpfova PP, Vychodilova I, Dvorackova M, Majerska J, Dokladal L, Schorova S, Fajkus J (2014) Telomere repeat binding proteins are functional components of Arabidopsis telomeres and interact with telomerase. Plant J 77:770-781. https://doi.org/10.1111/ tpj. 12428

Schrumpfova PP, Vychodilova I, Hapala J, Schorova S, Dvoracek V, Fajkus J (2016) Telomere binding protein TRB1 is associated with promoters of translation machinery genes in vivo. Plant Mol Biol 90:189-206. https://doi.org/10.1007/s11103-015-0409-8

Sharma M, Pandey A, Pandey GK (2014) beta-Catenin in plants and animals: common players but different pathways. Front Plant Sci 5:143. https://doi.org/10.3389/fpls.2014.00143
Simaskova M et al (2015) Cytokinin response factors regulate PINFORMED auxin transporters. Nat Commun 6:8717. https://doi. org/10.1038/ncomms 9717

Singh SK, Roy S, Choudhury SR, Sengupta DN (2010) DNA repair and recombination in higher plants: insights from comparative genomics of Arabidopsis and rice. BMC Genom 11:443. https:// doi.org/10.1186/1471-2164-11-443

Surovtseva YV, Shakirov EV, Vespa L, Osbun N, Song X, Shippen DE (2007) Arabidopsis POT1 associates with the telomerase RNP and is required for telomere maintenance. EMBO J 26:3653-3661. https://doi.org/10.1038/sj.emboj.7601792

Tenea GN, Spantzel J, Lee LY, Zhu Y, Lin K, Johnson SJ, Gelvin SB (2009) Overexpression of several Arabidopsis histone genes increases agrobacterium-mediated transformation and transgene expression in plants. Plant Cell 21:3350-3367. https://doi. org/10.1105/tpc.109.070607

Tewari R, Bailes E, Bunting KA, Coates JC (2010) Armadillo-repeat protein functions: questions for little creatures. Trends Cell Biol 20:470-481. https://doi.org/10.1016/j.tcb.2010.05.003

Trapp O, Seeliger K, Puchta H (2011) Homologs of breast cancer genes in plants. Front Plant Sci 2:19. https://doi.org/10.3389/ fpls.2011.00019

Tremousaygue D, Garnier L, Bardet C, Dabos P, Herve C, Lescure B (2003) Internal telomeric repeats and 'TCP domain' proteinbinding sites co-operate to regulate gene expression in Arabidopsis thaliana cycling cells. Plant J 33:957-966

Voinnet O, Lederer C, Baulcombe DC (2000) A viral movement protein prevents spread of the gene silencing signal in Nicotiana benthamiana. Cell 103:157-167

Yanhui C et al (2006) The MYB transcription factor superfamily of Arabidopsis: expression analysis and phylogenetic comparison with the rice MYB family. Plant Mol Biol 60:107-124. https:// doi.org/10.1007/s11103-005-2910-y

Yoshiyama KO, Sakaguchi K, Kimura S (2013) DNA damage response in plants: conserved and variable response compared to animals. Biology (Basel) 2:1338-1356. https://doi.org/10.3390/biology204 1338

Zachova D et al (2013) Structure-function relationships during transgenic telomerase expression in Arabidopsis. Physiol Plant 149:114-126. https://doi.org/10.1111/ppl.12021

Zaug AJ, Podell ER, Nandakumar J, Cech TR (2010) Functional interaction between telomere protein TPP1 and telomerase. Genes Dev 24:613-622. https://doi.org/10.1101/gad.1881810

Zhou Y, Hartwig B, James GV, Schneeberger K, Turck F (2016) Complementary activities of TELOMERE REPEAT BINDING proteins and polycomb group complexes in transcriptional regulation of target genes. Plant Cell 28:87-101. https://doi.org/10.1105/ tpc. 15.00787 